\title{
Laboratory investigation of self-healing properties on geosynthetic clay liners with flaw
}

\author{
Guang-Wei Zhang ${ }^{1,2}$, Hu-Yuan Zhang ${ }^{1 *}$, Jin-Fang Wang ${ }^{3}$, Lang Zhou ${ }^{1}$, Ping Liu ${ }^{1}$, Xiao Jiang ${ }^{1}$ \\ ${ }^{1}$ Lanzhou University, China \\ Key Laboratory of Mechanics on Disaster and Environment in Western China \\ ${ }^{2}$ PetroChina Research Institute of Exploration \& Development-Northwest, China \\ ${ }^{3}$ Lanzhou University, China \\ Key Laboratory of Western China's Environmental Systems \\ *Corresponding author’s e-mail: zhanghuyuan@|zu.edu.cn
}

Keywords: landfills, geosynthetic clay liner, self healing, hydraulic conductivity.

\begin{abstract}
The objective of this paper is to evaluate the self-healing properties of a commercially-available geosynthetic clay liner (GCL) using flexible-wall permeameter. The GCLs are produced by the same factory, but the contents of bentonite are different. Also the hydraulic conductivities (HC) of GCLs with no defect are different. In this study, specimens were completely saturated under the backpressure of $20 \mathrm{kPa}$ before the test. Permeability tests were performed on GCL specimens with penetrating flaw and also on specimens permeated with distilled water and $\mathrm{CaCl}_{2}$ solutions. The test results were presented and discussed. Experimental results showed that the GCL with penetrating flaw did not exhibit complete self-healing in the case of flaw. After 120 days, the hydraulic conductivity increased by approximately an order of magnitude. In addition, $\mathrm{CaCl}_{2}$ solutions had a significant influence on the hydraulic conductivity. The research findings might be of interest to researchers and engineers who design liners for landfills and other liquid containment facilities.
\end{abstract}

\section{Introduction}

Geosynthetic clay liners (GCLs) consisting of bentonite placed between two geotextiles are used in various barrier systems to provide containment of contaminated soil and water (Rowe et al. 2005). Use of GCLs in such applications is desirable due to their extremely low hydraulic conductivity, self-healing properties, simple and rapid installation, and easier quality assurance relative to CCLs (Malusis et al. 2007). Bentonite refers to the material that is primary smectite group of minerals. And the physical properties of bentonite were mainly determined by the smectite minerals. Characteristics of smectite minerals include large cation-exchange capacity, large specific surface area, high swelling potential, and low hydraulic conductivity (Gleason et al. 1997).

The quality of bentonite plays a significant role in the performance of GCLs. Lee and Shackelford (2005) found that the GCL with the higher quality bentonite is more susceptible to chemical attack than the GCL with the lower quality bentonite (Lee and Shackelford 2005). GCLs retain their hydraulic properties after freeze-thaw events largely due to the self-healing properties of the bentonite material used in their construction. In general, the tests showed that GCLs can withstand at least three freeze-thaw cycles without significant changes in hydraulic conductivity (Hewitt and Daniel 1997). In the laboratory, specimens of three GCLs were frozen and thawed 20 times, and no increase in hydraulic conductivity was measured. Examination of thawed GCLs showed no evident crack that is commonly found in thawed compacted clays (Kraus et al. 1997). The objective of this study was to examine the long-term performance of geosynthetic clay liners exposed to repeated freeze-thaw cycles, encompassing their application as a final cover as well as a bottom liner. Measurements of hydraulic conductivity were performed after as many as 150 freeze-thaw cycles, with no appreciable increases observed (Podgorney and Bennett 2006).

However, bentonites are sensitive to chemical composition of the pore liquid that influences the thickness of the adsorbed layer, because pore liquid that can cause the adsorbed layer to collapse and thus cause the hydraulic conductivity to increase. Therefore, the number of pore volumes of permeant flow and the level of chemical equilibrium have a significant effect on the hydraulic conductivity. Several studies have been conducted to assess the performance of GCLs permeated with water and some chemical solution. It showed that there is a decrease in hydraulic conductivity for small amounts of permeant flow for all ethanol/water mixtures examined (Petrov et al. 1997). Permeation with $\mathrm{CaCl}_{2}$ solution resulted in an increase in the hydraulic conductivity of one order of magnitude or more. The rate changes which occurred depended on the concentration, with slower changes occurring for weaker solutions. In contrast, permeation with $100 \mathrm{mM}$ $\mathrm{NaCl}$ or $\mathrm{KCl}$ solutions or deionized water resulted in no appreciable change in hydraulic conductivity, regardless of the 
duration of permeation or number of pore volumes of flow (Jo et al. 2005). The hydraulic conductivity of the conventional GCLs that were exhumed from the cover ultimately is on the order of $5 \times 10^{-5} \mathrm{~cm} / \mathrm{s}$. The high hydraulic conductivities apparently were caused by exchange of $\mathrm{Ca}$ for $\mathrm{Na}$ on the bentonite combined with dehydration. The overlying and underlying soils likely were the source of the $\mathrm{Ca}$ involved in the exchange (Benson et al. 2007).

Effective stress is a significant variable that controls the behavior of bentonite (Shackelford et al. 2000), decreasing both hydraulic conductivity and the susceptibility of bentonite to chemical alterations; because increasing the effective stress on a GCL decreases the void ratio within the bentonite layer. The hydraulic conductivity of the sodium bentonite used in most GCLs is on the order of $10^{-9} \mathrm{~cm} / \mathrm{s}$ when permeated with deionized water at stresses typical of cover applications (Rowe 2005).

To assess the self-healing capacity of GCLs, direct measurements of hydraulic conductivity or permittivity are helpful. Some authors examined the self-healing properties of bentonite by making three holes with different diameters and allowed the specimens to rehydrate under a confining stress of $14 \mathrm{kPa}$. The measured hydraulic conductivity values indicated: (i) the bentonite rehydrated to fill the 12 and $25 \mathrm{~mm}$-diameter holes; (ii) there was no significant change in hydraulic conductivity. However, for the $75 \mathrm{~mm}$-diameter hole, hydraulic conductivity increased to $10^{-9} \mathrm{~cm} / \mathrm{s}$. It showed that the final void ratios in a needle-punched GCL are much less than the corresponding values in a similar GCL without needle punching at the same effective stress (Benson and Meer 2009).

In this study, permittivity tests were performed on GCL specimens with flaw. This paper is to evaluate the hydraulic conductivity of GCLs completely saturated under a low effective stress. Meanwhile, the influence of $\mathrm{CaCl}_{2}$ solutions was also concerned in the test.

\section{Materials and methods}

\section{Geosynthetic Clay Liner}

The GCL used in this study is sold commercially and is a reinforced (needle-punched) GCL consisting of a layer of granular sodium bentonite between two nonwoven polypropylene geotextiles. The GCL bentonite is classified as a highplasticity clay $(\mathrm{CH})$ according to the Unified Soil Classification System (ASTM D2487). For the sample roll utilized in this study, the average oven-dried bentonite mass per unit area was $5.00 \mathrm{~kg} / \mathrm{m}^{2}$ based on three bentonite samples collected from the sample roll. This value was used as the baseline bentonite mass per unit area for the GCL in this study. The natural water content of the bentonite in GCL was about $12.00 \%$ at the time of specimen preparation. The water content of the bentonite in GCL was determined by oven drying method according ASTM D 2216. The water content in soil can be expressed as $\omega=\mathrm{M}_{\mathrm{w}} / \mathrm{M}_{\mathrm{s}} \times$ $100 \%$, where: $\omega=$ water content $(\%) ; M_{w}=$ mass of water in soil $(\mathrm{kg}) ; \mathrm{M}_{\mathrm{s}}=$ dry mass of soil $(\mathrm{kg})$. The physical property of the GCL can be seen from Table 1. The mass per unit area and water content were determined in lab in accordance with the standard for soil test method GB/T 50123-1999 of China.

\section{Hydraulic conductivity tests}

Specimens of the GCLs with nominal diameters of $103 \mathrm{~mm}$ were permeated using the falling-head procedure with flexible-wall permeameter (Fig.1) as described in ASTM D5084-2010. Flexible-wall permeameter has the following advantages: (1) can be side-wall leakage prevented or minimized; (2) stress on specimen can be controlled; (3) volume change or deformation can be measured. Therefore, flexible-wall permeameter is more useful to determine the hydraulic conductivity than rigid-wall permeameter when the material has a hydraulic conductivity less than $10^{-4} \mathrm{~cm} / \mathrm{s}$. The test method may be utilized on all specimen types (undisturbed, reconstituted, remolded, compacted, etc.). The specimens were prehydrated by distilled water (DW) and then put in a humidor for 48 hours. Before the test, specimens were exposed to the distilled water for at least 7 days by opening the influent port and keeping effluent port closed under $20 \mathrm{kPa}$. Backpressure was kept in $20 \mathrm{kPa}$ through the whole test. The thickness of specimens was measured before and after the hydraulic conductivity tests using a calliper and a ruler. All the specimens were permeated at an average hydraulic gradient of 500 such that the average effective stresses at the cell, bottom (inflow), and top (outflow) of the specimens were $35 \mathrm{kPa}, 15 \mathrm{kPa}$, and $0 \mathrm{kPa}$, respectively. After the specimen was fully saturated, the hydraulic conductivity tests began. In the first 30 days, the specimens were the GCL with no defect and the permeant liquid was distilled water. In the 90th day, the samples were demounted and divided into two parts. The penetrating flaw represents the extent of damage in the form of tears in field conditions. And the saturation time was 120 days. In the period, the self-healing may change. In the 210th and 250th day, distilled water and $\mathrm{CaCl}_{2}$ solution were used in the test, respectively.

In this test, the flow velocity $(\mathrm{v})$ is directly proportional to the hydraulic gradient I. Darcy's law, describing the flow rate through a porous medium, could be written as follows: $\mathrm{v}=\mathrm{k} \times \mathrm{I}$, where $\mathrm{k}$ is the hydraulic conductivity $(\mathrm{cm} / \mathrm{s})$. The water head of the influent at certain time intervals is recorded to calculate the hydraulic conductivity of the specimen according to Darcy's law. The flow rate through the section

Table 1. Physical property of the GCL

\begin{tabular}{cccc}
\hline Characteristic & $\begin{array}{c}\text { thickness after test } \\
(\mathrm{cm})\end{array}$ & $\begin{array}{c}\text { mass per unit area } \\
\left(\mathrm{kg} / \mathrm{m}^{2}\right)\end{array}$ & $\begin{array}{c}\text { water content } \\
(\%)\end{array}$ \\
\hline & & Before test & Final test \\
GCL1 & 1.00 & 7.60 & 204 \\
GCL2 & 1.10 & 8.50 & 229 \\
Stardard of experiment & & GB/T50123-1999 & GB/T50123-1999 \\
\hline
\end{tabular}




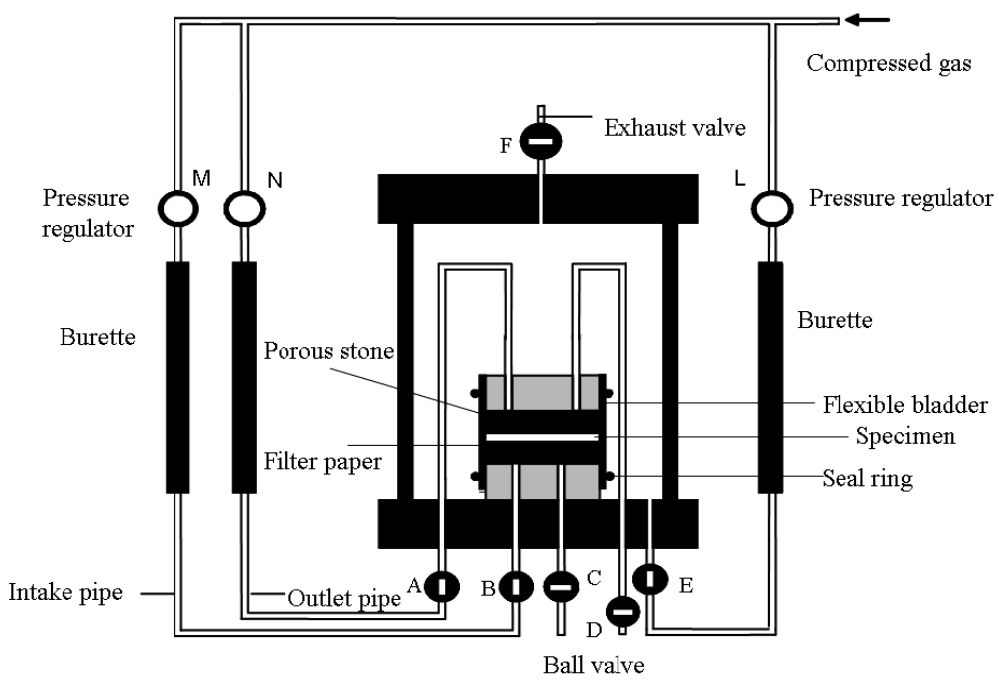

Fig.1. Schematic diagram of flexible-wall permeameter

of the inflow tube is equal to the flow rate through section of outflow. The governing equations are shown as Equation 1 through Equation 5:

$$
\begin{gathered}
q=\frac{d V}{d t} \\
q_{1}=a \frac{d h}{d t} \\
q_{2}=k A \frac{h}{L} \\
q_{2} \rightarrow-\frac{d h}{h}=\frac{k A}{L a} d t \\
k=\frac{a \cdot L}{A \cdot\left(t_{1}-t_{0}\right)} \ln \left(\frac{h_{0}}{h_{1}}\right)
\end{gathered}
$$

Where: $q_{1}, q_{2}=$ flow rate in the inflow and in the specimen, respectively $\left(\mathrm{cm}^{3} / \mathrm{s}\right) ; a=$ cross-sectional area of the inflow tube $\left(\mathrm{cm}^{2}\right) ; L=$ length of specimen $(\mathrm{cm}) ; \mathrm{A}=$ the area of the specimen $\left(\mathrm{cm}^{2}\right) ; h_{0}, h_{1}=$ head levels measured in the flow tube $(\mathrm{cm}) ; t_{0}$, $t_{1}=$ time when water is at head level of $h_{0}$ and $h_{l}$, respectively; $\ln =$ natural logarithm (base $e=2.71828)$.

In this study, there is a gas pressure on the hydraulic head. $1 \mathrm{kPa}$ of gas pressure is about $10 \mathrm{~cm}$ hydraulic head. So, the hydraulic conductivity of the GCL can be defined as follows:

$$
k=2.3 \frac{a L}{A\left(t_{1}-t_{0}\right)} \lg \frac{\left(h_{\text {in }}-h_{\text {out }}\right)_{\text {initial }}+10 p_{\text {initial }}}{\left(h_{\text {in }}-h_{\text {out }}\right)_{\text {final }}+10 p_{\text {final }}}
$$

Where: $k=$ hydraulic conductivity $(\mathrm{cm} / \mathrm{s}) ; h_{i n}, h_{\text {out }}=$ hydraulic heads in the intake and outlet pipe $(\mathrm{cm})$, respectively; $p_{\text {in }}$ and $p_{\text {out }}=$ the gas pressure on the hydraulic head $(\mathrm{kPa}) ; \lg =$ base 10 logarithm.

\section{Results and discussion}

\section{Effect of the water content on microstructure}

The hydraulic performance of a GCL is influenced by the degree of hydration (Sivakumarr 2001). Insufficient GCL hydration may lead to high leakage rates through GCLs. In this part, we focused on the microstructures of the GCL with different water contents. Scanning electron microscope (SEM) technology was used to provide qualitative results of the pore properties for different water content of GCL. Two kinds of magnification $(\times 20$ and $\times 50)$ were selected to illustrate the pore properties. The SEM micrographs of different water contents of GCL were presented below (Fig. 2). As showed in Fig.2, if the water content of GCL is less than $180 \%$, there is a higher permeability and in this case the coarser micro structure results. So, in this study, all of the specimens were permeated. Bentonites have low hydraulic conductivity when osmotic swelling occurs during hydration of the interlayer space between the montmorillonite lamella. Accumulation of water in the interlayer space causes the bentonite granules to swell, thereby reducing the size and conductance of the intergranular pores that act as the primary flow paths in GCLs (Benson et al., 2007).

\section{Hydraulic conductivity tests}

The results of the hydraulic conductivity test for specimens GCL1 and GCL2 were shown in Fig. 3 and Fig. 4. The specimens were under the same experimental condition, such that bottom (inflow), and top (outflow) of the specimens were $35 \mathrm{kPa}, 15 \mathrm{kPa}$, and $0 \mathrm{kPa}$, respectively.

Fig. 3 shows the HC of GCL1 change with time. It could be seen from Fig. 3 that the HC of GCL1 with no defect decreased with time in the period of tests. In the first day, the $\mathrm{HC}$ of GCL1 ranged from $1.4 \times 10^{-6} \mathrm{~cm} / \mathrm{s}$ to $1.7 \times 10^{-6} \mathrm{~cm} / \mathrm{s}$. And 30 days later, the $\mathrm{HC}$ of GCL1 decreased to $6.2 \times 10^{-7} \mathrm{~cm} / \mathrm{s}$. In the test process, $\mathrm{HC}$ of the GCL1 decreased slightly under backpressure of $20 \mathrm{kPa}$, and the $\mathrm{HC}$ keeps in half an order of magnitude. 


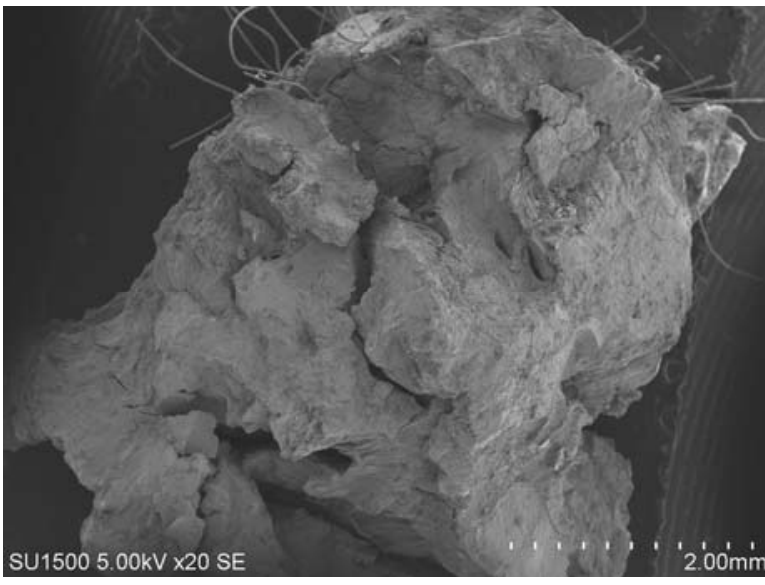

a. SEM of GCL with water content of $150 \%(\times 20)$

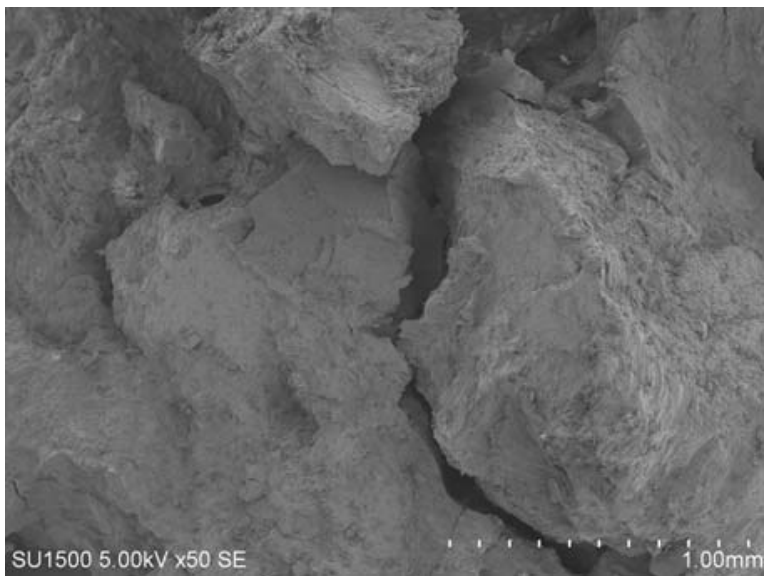

c. SEM of GCL with water content of $150 \%(\times 50)$

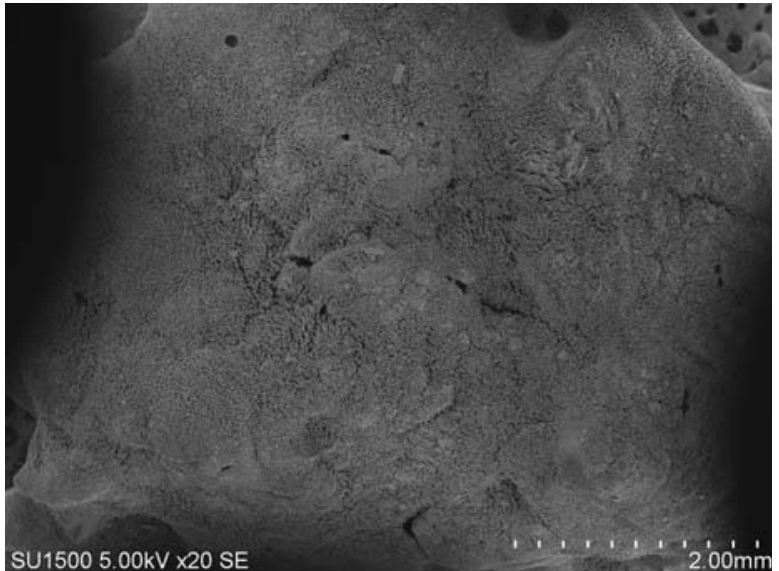

b. SEM of GCL with water content of $180 \%(\times 20)$

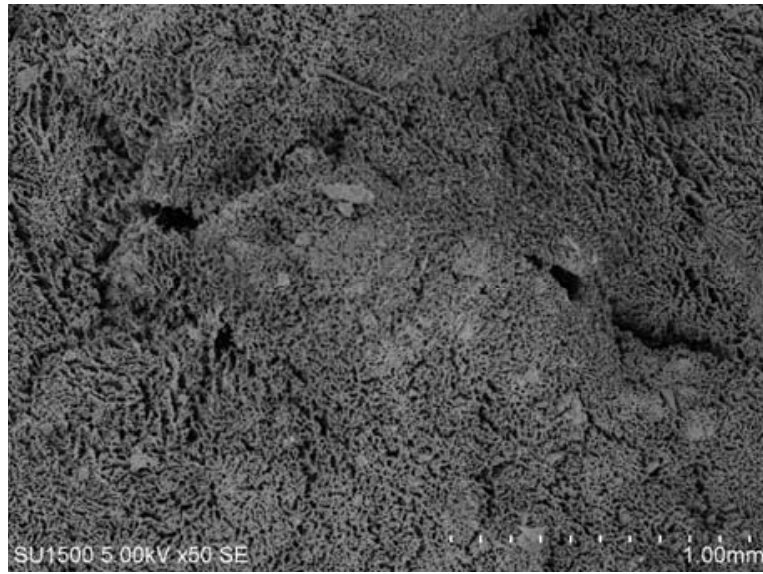

d. SEM of GCL with water content of $180 \%(\times 50)$

Fig. 2. SEM images of GCL specimens with different water content after the test

Seepage consolidation happened in the $\mathrm{HC}$ tests. Therefore, confining stress contributed to lower bulk GCL void ratios and hence lower hydraulic conductivity values. Compared to the GCL1 with no defect, the specimens with flaw were prehydrated with distilled water in 120 days. There was an increase in HC of GCL1, when kept under $9.8 \times 10^{-6}$ $\mathrm{cm} / \mathrm{s}$. It was approximately an order of magnitude. As for the $\mathrm{CaCl}_{2}$ solution, hydraulic conductivity of GCL1 with flaw was about $1.0 \times 10^{-5} \mathrm{~cm} / \mathrm{s}$.

Fig. 4 shows the HC of GCL2 changes with time. It could be seen from Fig. 4 that the HC of GCL1 with no defect decreased with time in the period of tests. In the first day, the $\mathrm{HC}$ of GCL1 ranged from $1.6 \times 10^{-7} \mathrm{~cm} / \mathrm{s}$ to $3.0 \times 10^{-7} \mathrm{~cm} / \mathrm{s}$. And after the first 30 days, the HC of GCL1 decreased to $7.5 \times 10^{-8}$ $\mathrm{cm} / \mathrm{s}$. In the test process, HC of the GCL2 slightly decreased under backpressure of $20 \mathrm{kPa}$, and the $\mathrm{HC}$ kept in half an order of magnitude. Seepage consolidation happened in the $\mathrm{HC}$ tests. So, confining stress contributed to lower bulk GCL void ratios and consequently lower hydraulic conductivity. Compared to the GCL2 with no defect, the specimens with flaw were prehydrated with distilled water in the 120th day. There was an increase in $\mathrm{HC}$ of GCL1, and the $\mathrm{HC}$ was less than $8.5 \times 10^{-7} \mathrm{~cm} / \mathrm{s}$. As for the $\mathrm{CaCl}_{2}$ solution, hydraulic conductivity of GCL1 with flaw was about $1.0 \times 10^{-6} \mathrm{~cm} / \mathrm{s}$.
One factor that results in an increase in hydraulic conductivity is exchange of the monovalent $\mathrm{Na}$ cation initially on the montmorillonite surface with divalent cations such as $\mathrm{Ca}$ (Benson et al. 2007). As a consequence of the ion exchange of sodium bentonite for a calcium bentonite a certain reduction in volume due to the decreasing distances between the montmorillonite flakes and a loss of water can be observed. At the same time, the microstructure is changed from smaller, finely distributed clay mineral flakes to larger clay mineral crystals. This coarser microstructure results in a higher permeability (Egloefstein 2001). We can see that GCL1 with penetrating flaw considered did not exhibit complete self-healing in the case of flaw.

The results suggest that GCL with penetrating flaw may pose significant problems and its self healing is unlikely, and it is different from observations made by G. L. Sivakumar (Sivakumarr 2001) who focused on the performance of GCL specimens with different diameters hole.

\section{Conclusions}

GCL Specimens were completely saturated under backpressure of $20 \mathrm{kPa}$ in the test. Permittivity tests were performed on GCL specimens with penetrating flaw and also on specimens permeated with distilled water and $\mathrm{CaCl}_{2}$ solutions. It could 


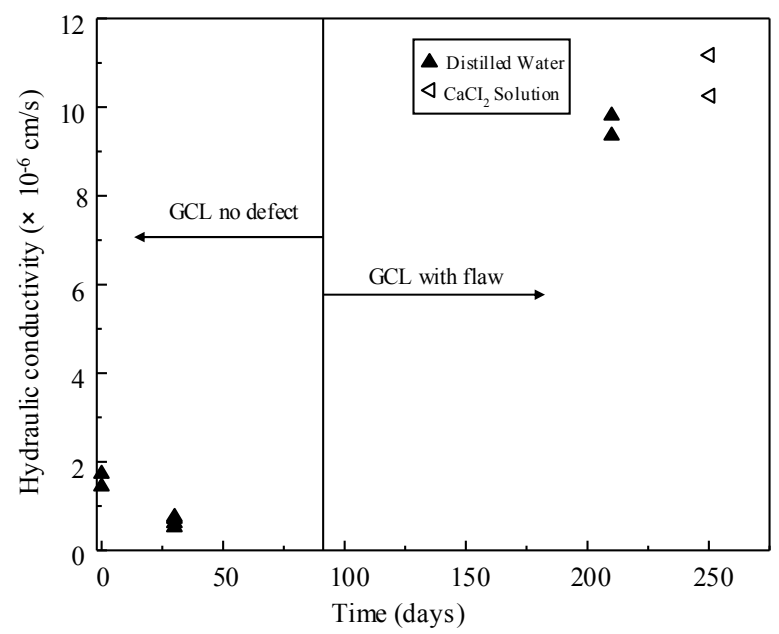

Fig.3. Hydraulic conductivity versus time for GCL1 permeated with distilled water and $\mathrm{CaCl}_{2}$ solution

be seen that the hydraulic conductivities of GCLs with no defect range from $10^{-7} \mathrm{~cm} / \mathrm{s}$ to $10^{-6} \mathrm{~cm} / \mathrm{s}$. After 120 days, the hydraulic conductivity of GCL specimens with penetrating flaw increased approximately by an order of magnitude. It did not exhibit complete self-healing in the case of flaw.

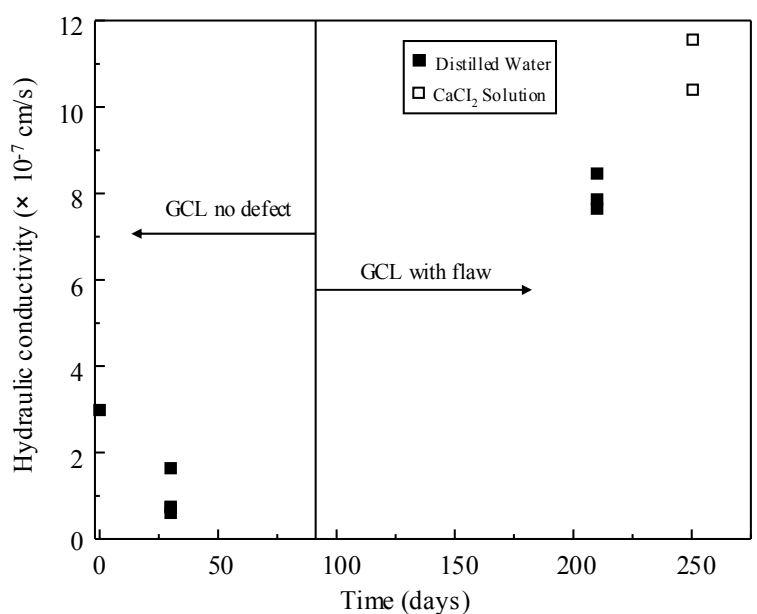

Fig. 4. Hydraulic conductivity versus time for GCL2 permeated with distilled water and $\mathrm{CaCl}_{2}$ solution

In addition, the $\mathrm{CaCl}_{2}$ solutions had a significant influence on the hydraulic conductivity as exchangeable cations. When the specimens were permeated with $\mathrm{CaCl}_{2}$ solution, there was an increase in the hydraulic conductivity of GCL.

\section{Acknowledgments}

The research was supported by the Doctoral Program of Higher Education of China (grant no. 20110211110025). Sincere thanks to the reviewers for their time and courtesy, for assisting the authors to maintain the quality of the paper. The authors would like to thank Bo YANG, Shibin ZHU, Xuechao ZHANG and Yi CHEN from Lanzhou University for their help.

\section{References}

[1] Benson, C. \& Meer, S. (2009). Relative abundance of monovalent and divalent cations and the impact of desiccation on geosynthetic clay liners, Journal of Geotechnical and Geoenvironmental Engineering, 135, 3, pp. 349-358.

[2] Benson, C., Thorstad, P., Jo, H. \& Rock, S. (2007). Hydraulic performance of geosynthetic clay liners in a landfill final cover, Journal of Geotechnical and Geoenvironmental Engineering, 133, 7, pp. 814-827.

[3] Egloefstein, T. (2001). Natural bentonites-influence of the ion exchange and partial desiccation on permeability and self-healing capacity of bentonites used in GCLs, Geotextiles and Geomembranes, 19,7 , pp. 427-444.

[4] Gleason, M., Daniel, D. \& Eykholt, G. (1997). Calcium and sodium bentonite for hydraulic containment applications, Journal of Geotechnical and Geoenvironmental Engineering, 123, 5, pp. 438-445.

[5] Hewitt, R. \& Daniel, D. (1997). Hydraulic conductivity of geosynthetic clay liners after freeze-thaw, Journal of Geotechnical and Geoenvironmental Engineering, 123, 4, pp. 305-313.

[6] Jo, H., Benson, C., Shackelford, C., Lee, J. \& Edil, T. (2005). Long-term hydraulic conductivity of a geosynthetic clay liner permeated with inorganic salt solutions, Journal of Geotechnical and Geoenvironmental Engineering, 131, 4, pp. 405-417.

[7] Kraus, J., Benson, C., Erickson, A. \& Chamberlain, E. (1997). Freeze-thaw cycling and hydraulic conductivity of bentonitic barriers, Journal of Geotechnical and Geoenvironmental Engineering, 123, 3, pp. 229-238.

[8] Lee, J. \& Shackelford, C. (2005). Impact of bentonite quality on hydraulic conductivity of geosynthetic clay liners, Journal of Geotechnical and Geoenvironmental Engineering, 131, 1, pp. 64-77.

[9] Malusis, M. A. \& Scalia, J. (2007). Hydraulic conductivity of an activated carbon-amended geosynthetic clay liner, Geoenvironmental Engineering, 163, pp. 1-13.

[10] Petrov, R., Rowe, R. \& Quigley, R. (1997). Selected factors influencing GCL hydraulic conductivity, Journal of Geotechnical and Geoenvironmental Engineering, 123, 8, pp. 683-695. 
[11] Podgorney, R. \& Bennett, J. (2006). Evaluating the long-term performance of geosynthetic clay liners exposed to freeze-thaw, Journal of Geotechnical and Geoenvironmental Engineering, 132, 2, pp. 265-268.

[12] Rowe, R., Mukunoki, T. \& Sangam, H. (2005). Benzene, toluene, ethylbenzene, m\&p-xylene, o-xylene diffusion and sorption for a geosynthetic clay liner at two temperatures, Journal of Geotechnical and Geoenvironmental Engineering, 131, 10, pp. 1211-1221.

[13] Rowe, R.K. (2005). Long-term performance of contaminant barrier system, Geotechnique, 55, 9 , pp. 631-678.

[14] Shackelford, C., Benson, C., Katsumi, T., Edil, T. \& Lin, L. (2000). Evaluation of the hydraulic conductivity of GCLs permeated with non-standard liquids, Geotextiles and Geomembranes, 18, 2-4, pp. 133-161.

[15] Sivakumar, G. L., Sporer, H., Zanzinger, H. \& Gartung, E. (2001). Self-healing properties of geosynthetic clay liners, Geosynthetics International, 8, 5, pp. 461-470. 